\title{
CAMA
}

Centre for Applied Macroeconomic Analysis

\section{Short- and Long-Run Tradeoff Monetary Easing}

\section{CAMA Working Paper 45/2015 November 2015}

\section{Koki Oikawa}

Waseda University

\section{Kozo Ueda}

School of Political Science and Economics, Waseda University and Centre for Applied Macroeconomic Analysis (CAMA), ANU

\section{Abstract}

In this study, we illustrate a tradeoff between the short-run positive and long-run negative effects of monetary easing by using a dynamic stochastic general equilibrium model embedding endogenous growth with creative destruction and sticky prices due to menu costs. While a monetary easing shock increases the level of consumption because of price stickiness, it lowers the frequency of creative destruction (i.e., product substitution) because inflation reduces the reward for innovation via menu cost payments. The model calibrated to the U.S. economy suggests that the adverse effect dominates in the long run. 


\section{Keywords}

Schumpeterian, new Keynesian, non-neutrality of money

\section{JEL Classification}

E31, E58, O33, O41

\section{Address for correspondence:}

(E) cama.admin@anu.edu.au

The Centre for Applied Macroeconomic Analysis in the Crawford School of Public Policy has been established to build strong links between professional macroeconomists. It provides a forum for quality macroeconomic research and discussion of policy issues between academia, government and the private sector.

The Crawford School of Public Policy is the Australian National University's public policy school, serving and influencing Australia, Asia and the Pacific through advanced policy research, graduate and executive education, and policy impact. 


\title{
Short- and Long-Run Tradeoff of Monetary Easing*
}

\author{
Koki Oikawa ${ }^{\dagger}$ and Kozo Ueda ${ }^{\ddagger}$
}

November 17, 2015

\begin{abstract}
In this study, we illustrate a tradeoff between the short-run positive and long-run negative effects of monetary easing by using a dynamic stochastic general equilibrium model embedding endogenous growth with creative destruction and sticky prices due to menu costs. While a monetary easing shock increases the level of consumption because of price stickiness, it lowers the frequency of creative destruction (i.e., product substitution) because inflation reduces the reward for innovation via menu cost payments. The model calibrated to the U.S. economy suggests that the adverse effect dominates in the long run.
\end{abstract}

Keywords: Schumpeterian; new Keynesian; non-neutrality of money JEL classification: E31, E58, O33, O41

${ }^{*}$ We thank Hiroki Arato, Ippei Fujiwara, Tatsuro Iwaisako, Kazuo Mino, Yoshiyasu Ono, and the seminar and conference participants at the Bank of Korea and Hitotsubashi University.

${ }^{\dagger}$ Waseda University (Email: oikawa.koki@gmail.com)

${ }^{\ddagger}$ School of Political Science and Economics, Waseda University and Centre for Applied Macroeconomic Analysis (CAMA) (Email: kozo.ueda@waseda.jp) 


\section{Introduction}

The Great Recession during 2007-09 prompted many central banks to conduct unprecedented levels of monetary easing. Although this helped in preventing an economic catastrophe such as the Great Depression, many economies have experienced only slow and modest recoveries (i.e., they faced secular stagnation) since then. Japan has fallen into even longer stagnations, namely the lost decades. Firm entry and productive investment have been inactive since the burst of the asset market bubble around 1990 despite a series of monetary easing measures (Caballero et al. (2008)).

In this study, we consider the possibility that monetary easing induces adverse long-run effects on real economic activity by discouraging creative destruction. To this end, we construct a dynamic stochastic general equilibrium model that embeds both Schumpeterian and new Keynesian features: endogenous growth due to creative destruction and sticky prices due to menu costs, respectively. Then, we conduct numerical simulation for the model calibrated to the U.S. economy to compute the stationary equilibrium and transition paths when transitory monetary easing shocks hit the economy.

Our model illustrates a tradeoff between the short-run positive effects and long-run negative effects of a transitory monetary easing shock. On the one hand, monetary easing increases the level of consumption due to price stickiness. Although the fraction of price-revising firms increases endogenously, thus offsetting the real effect of the monetary easing shock partially, monetary policy is not neutral. Because an increasing number of firms exit over time, the density of marginal firms that would subsequently revise their prices is relatively low. This non-uniform firm distribution reduces the increase in price-revising firms in response to the monetary easing shock. Therefore, the increase in the extensive margin does not completely eliminate the real effect, yielding a positive short-run effect.

On the other hand, inflation due to monetary easing reduces the reward for innovation via menu cost payments. As monetary easing increases marginal costs, firms incur more menu cost payments owing to a need for more frequent price changes. This decreases potential entrants' value and thus sacrifices their innovations. Such a Schumpeterian feature combined with menu cost violates the super-neutrality of money even in the long-run. The monetary easing lowers the frequency of creative destruction (product substitution), and in turn, the growth rate of consumption.

According to the numerical simulation calibrated to the U.S. economy, we find that the latter adverse effect dominates the former positive effect in the long-run. A $1 \sigma$ transitory monetary easing shock for a quarter (a weekly $0.03 \%$ point increase in money growth rate) boosts the level of consumption by $0.05 \%$ in the short run but dampens it by $0.07 \%$ permanently. 
Our study is related to the following three strands of the literature. The first strand concerns menu cost models. As in Golosov and Lucas (2007), Nakamura and Steinsson (2010), and Midrigan (2011), we solve a dynamic optimization problem numerically and simulate the effects of monetary policy. Although Caplin and Spulber (1987) find the neutrality of monetary policy in a simple menu cost model, this result can be reversed by simply introducing the entry and exit of firms, because firm distribution is non-uniform.

Second, our model of creative destruction is based on Grossman and Helpman (1991), where firm entry and exit are endogenous. Firms enter the market by inventing a new product superior in quality to the previous one, while a firm producing an older version of products exits. The growth rate of the real economy is determined endogenously. With this endogenous growth setting, we can consider a reallocation from old to new firms with better quality or productivity. Since the long-run negative effect of monetary easing mainly comes from dampening creative destruction by potential entrants, monetary easing works as a bailout for incumbents. Although the incumbents are solvent (thus, not "zombies") in our model, ${ }^{1}$ a reallocation through creative destruction with appropriate frequency is desirable for social welfare. Acemoglu et al. (2013) extend Lentz and Mortensen (2008) to investigate the effects of subsidy on the incumbents' and the entrants' R\&D separately and find that the former reduces the overall growth rate. Our study implies that monetary easing has a similar effect under price stickiness because it increases the incumbents' survival rate through a decline in the entry rate.

The third strand is a combination of the above two model types. The importance of product substitution (turnover) has been pointed out by Bils and Klenow (2004), Nakamura and Steinsson (2008), and Bils (2009), who examine price developments at a micro level. Despite the importance of product substitution, to the best of our knowledge, no theoretical study exists on the effects of frequent product substitution on inflation and the real aggregate economy. To study this, our study examines the entry and exit of firms and price stickiness in combination. A deterministic version of our model is extensively studied in Oikawa and Ueda (2015) both analytically and numerically. Chu and Cozzi (2014) use a model with creative destruction and money, but without price stickiness such as menu cost. ${ }^{2}$

This paper is structured as follows. Section 2 provides the basic setup of the model, and Section 3 provides the analytical results of two simplified models: an exogenous firm entry/exit

\footnotetext{
${ }^{1}$ Caballero et al. (2008) argue that zombie firms had decayed economic recovery during the lost decades in Japan.

${ }^{2}$ Other related studies include Arato (2009), Funk and Kromen (2010), Amano et al. (2012), Vaona (2012), and Bilbiie et al. (2014). As for nominal rigidity, none of them is based on a menu cost model. They assume Calvo-, Rotemberg-, or Taylor-type price stickiness. Among them, Bilbiie et al. (2014) construct another type of endogenous growth model, a product-variety model, and combine this with Rotemberg-type price stickiness. However, their product-variety model explains neither the endogenous exit of firms (products) nor the endogenous growth rate of consumption.
} 
model and a deterministic model with endogenous entry. Section 4 formulates the full model. Section 5 discusses the real effects of monetary policy shocks, and Section 6 concludes the paper.

\section{Model}

Time is discrete, $t=0,1,2, \cdots$. A representative household consumes and supplies labor. Firms develop a new product by R\&D investment and enter the market. At the same time, firms with an old product exit. A central bank controls money supply growth. ${ }^{3}$ Exogenous aggregate shocks are monetary policy shocks.

Let us now clarify the model differences from our earlier study, Oikawa and Ueda (2015). First, the model in this study is stochastic. We solve the optimal pricing and distribution of firms in the presence of the stochastic shock on money growth and compute a transition path from one state to another. Second, time is discrete; we need this for numerical simulation. Third, money plays a real role in this model. Following the previous studies on menu cost, such as Sheshinski and Weiss (1977), Caplin and Spulber (1987), Golosov and Lucas (2007), Nakamura and Steinsson (2010), and Midrigan (2011), we assume that the nominal spending of households is equal to the money supply and that the central bank controls money supply growth. In contrast, in Oikawa and Ueda (2015), the central bank follows an inflation targeting policy and money is absent. These assumptions make the aggregate labor quantity redundant, and this simplifies computation.

\section{$2.1 \quad$ Firm Entry}

The firm entry and exit model is based on Grossman and Helpman (1991). A team of $h$ researchers can get an idea for a new product with a probability of 1 . Firms can enter the product markets freely, leading to $W_{t} h / P_{t} \geq V_{t}^{E}$, where $W_{t}, P_{t}$, and $V_{t}^{E}$ represent the nominal wage, the aggregate price index embedding quality improvement, and the expected present value of industry-leading firms at entry, respectively. Equality holds when the entry rate of firms, $\mu_{t}$, is positive. Otherwise, $\mu_{t}$ is zero. We define $v_{t}^{E}$ by $v_{t}^{E} \equiv P_{t} V_{t}^{E} / E_{t}$, where $E_{t}$ represents the aggregate nominal demand, which equals the money supply, $M_{t}$, following the resource constraint stated below. Now, the above free-entry condition can be rewritten as

$$
\frac{W_{t}}{M_{t}} h \geq v_{t}^{E} .
$$

\footnotetext{
${ }^{3}$ This assumption is introduced for simplicity. In reality, central banks do not have perfect control over money supply (broad money), although recent experiences show that they can control base money. The zero lower bound of nominal interest rates is also neglected in our model.
} 
When $\mu_{t}=0$, the above condition holds with strict inequality.

\subsection{Household}

A representative household has the following preferences over all versions of $k \in\left[0,1, \cdots, K_{t}(j)\right]$ of each product line $j \in[0,1]$ :

$$
\begin{gathered}
U_{t}=\mathbb{E}_{t}\left[\sum_{i=0}^{\infty} \beta^{i}\left(\log C_{t+i}-\chi L_{t+i}\right)\right], \\
C_{t}=\left[\int_{0}^{1}\left[\sum_{k=0}^{K_{t}(j)}\left(\tilde{q}(j, k) x_{t}(j, k)\right)^{\frac{\theta-1}{\theta}}\right] d j\right]^{\frac{\theta}{\theta-1}},
\end{gathered}
$$

where $\beta \in(0,1)$ and $\theta \geq 0$ represent the subjective discount factor and the elasticity of substitution between goods, respectively; $C_{t}$ is aggregate consumption; and $x_{t}(j, k)$ and $\tilde{q}(j, k)$ denote the consumption and quality of version $k$ in product line $j$, respectively. Quality evolves as

$$
\tilde{q}(j, k)=\tilde{q}(j, k-1) q(j, k),
$$

where $q(j, 0)=1$ for any $j$ and $q(j, k)>1$ represents a step size of the quality over the secondbest firm. In other words, when a new product is invented in product line $j$, its quality exceeds that of the existing firm by $q(j, k)$. The quality gap is constant over time once the new product draws it from some distribution at entry. For notational simplicity, we write $q_{t}(j) \equiv q\left(j, K_{t}(j)\right)$. Only the state-of-the-art technology is significant in equilibrium as in Grossman and Helpman (1991).

The budget constraint is

$$
P_{t} C_{t}+B_{t}=R_{t-1} B_{t-1}+W_{t} L_{t}+\Pi_{t}
$$

where $B_{t}, R_{t}$, and $\Pi_{t}$ represent the nominal savings, nominal interest rate, and dividend from firms, respectively. We assume that nominal spending must be equal to the money supply:

$$
P_{t} C_{t}=M_{t}
$$

The intertemporal optimization of consumption yields $\Lambda_{t}=\beta^{t} /\left(C_{t} P_{t}\right)$, where $\Lambda_{t}$ represents the stochastic discount factor. 
Because disutility from labor supply is linear, ${ }^{4}$ we have

$$
\chi C_{t}=W_{t} / P_{t} .
$$

Combined with equation (6), we have

$$
W_{t}=\chi M_{t}
$$

Nominal wage is proportional to the money supply.

The Euler equation is described as

$$
\frac{1}{C_{t}}=\mathbb{E}_{t}\left[\frac{\beta R_{t} P_{t}}{P_{t+1}} \frac{1}{C_{t+1}}\right]
$$

which becomes

$$
1=\mathbb{E}_{t}\left[\beta R_{t} e^{-g_{t+1}}\right]
$$

from equation (6), where we define the growth rate of money supply, $g_{t}$, by

$$
g_{t} \equiv \log \left(M_{t} / M_{t-1}\right)
$$

This is subject to the monetary policy shock, which we will specify subsequently.

\subsection{Industry-Leading Firms}

Firms produce one unit of goods using one unit of labor. We denote the posted price of version $k$ in product line $j$ by $p_{t}(j, k)$ and the real period profits of industry-leading firms with $k=K_{t}(j)$ by $\Pi_{t}\left(p_{t}(j, k), q_{t}(j)\right)$. Because of competition from rival firms, the firm profit is zero unless

$$
p_{t}(j, k) \leq q_{t}(j) W_{t}=q_{t}(j) \chi M_{t} .
$$

Combined with the competition between different product lines, the optimal price should satisfy

$$
p_{t}(j, k)=\min \left(q_{t}(j), \frac{\theta}{\theta-1}\right) \chi M_{t},
$$

without nominal rigidity. If $\theta \leq 1, p_{t}(j, k)$ should be equal to $q_{t}(j) \chi M_{t}$.

To incorporate nominal rigidity, we assume that firms hire labor when they reset their prices as much as $\kappa / \chi{ }^{5}$ We call this the menu cost. Let $\Omega_{t}$ denote firm distribution in terms of price

\footnotetext{
${ }^{4}$ According to Oikawa and Ueda (2015), our basic results hold true even when we assume a more general form for labor supply disutility.

${ }^{5}$ This definition implies that menu cost payment $(W \kappa / \chi)$ relative to total revenue $(M)$ equals $\kappa$.
} 
and quality in period $t$. Furthermore, let $v_{t}^{R}\left(q_{t}(j), \Omega_{t-1}, M_{t}\right)$ and $v_{t}^{N}\left(p_{t-1}(j), q_{t}(j), \Omega_{t-1}, M_{t}\right)$ denote the real value of firm $j$ when the firm reset and does not reset its price, respectively. Now, we have

$$
v_{t}=\max \left(v_{t}^{R}, v_{t}^{N}\right),
$$

$$
\begin{aligned}
& v_{t}^{R}\left(q_{t}(j), \Omega_{t-1}, M_{t}\right) \\
& \quad=\max _{p} \frac{P_{t}}{M_{t}}\left[\Pi_{t}\left(p, q_{t}(j)\right)-\frac{\kappa}{\chi} \frac{W_{t}}{P_{t}}+\mathbb{E}_{t}^{j}\left(\left(1-\mu_{t+1}\right) \frac{\Lambda_{t+1}}{\Lambda_{t}} \frac{P_{t+1}}{P_{t}} \frac{M_{t+1}}{P_{t+1}} v_{t+1}\left(p, q_{t}(j), \Omega_{t}, M_{t+1}\right)\right)\right],
\end{aligned}
$$

$$
\begin{aligned}
& v_{t}^{N}\left(p_{t-1}(j), q_{t}(j), \Omega_{t-1}, M_{t}\right) \\
& \quad=\frac{P_{t}}{M_{t}}\left[\Pi_{t}\left(p_{t-1}(j), q_{t}(j)\right)+\mathbb{E}_{t}^{j}\left(\left(1-\mu_{t+1}\right) \frac{\Lambda_{t+1}}{\Lambda_{t}} \frac{P_{t+1}}{P_{t}} \frac{M_{t+1}}{P_{t+1}} v_{t+1}\left(p_{t-1}(j), q_{t}(j), \Omega_{t}, M_{t+1}\right)\right)\right] .
\end{aligned}
$$

The firm value at entry equals

$$
v_{t}^{E}\left(\Omega_{t-1}, M_{t}\right)=\mathbb{E}_{t} \max _{p} \frac{P_{t}}{M_{t}}\left[\Pi_{t}(p, q)+\left(1-\mu_{t+1}\right) \frac{\Lambda_{t+1}}{\Lambda_{t}} \frac{P_{t+1}}{P_{t}} \frac{M_{t+1}}{P_{t+1}} v_{t+1}\left(p, q, \Omega_{t}, M_{t+1}\right)\right],
$$

where $q$ is a random variable since it is unknown before entry. We consider the case in which the probability of $q \leq 1$ is negligible.

\subsection{Monetary Policy}

Money supply grows as

$$
\log \left(M_{t} / M_{t-1}\right)=g_{t}=(1-\rho) g+\rho g_{t-1}+\varepsilon_{t}^{M}
$$

where $\varepsilon_{t}^{M}$ represents a monetary policy shock that follows $\varepsilon_{t}^{M} \sim N\left(0, \sigma_{M}\right)$.

\section{Simple Cases: Short- and Long-Run Impacts}

Before analyzing the full model described above, we present the key ingredients of our approach using simplified models to shed light on the short- and long-run impacts of monetary easing separately. Section 3.1 illustrates that money is not neutral under an exogenous entry/exit rate so that monetary easing has a positive real effect in the short run. Section 3.2 introduces 
an endogenous entry rate and illustrates that money is not super-neutral, either. A permanent increase in a money growth rate has a negative impact on the real growth. For computational simplicity, we develop the model in a continuous time setting.

\subsection{Simple Case 1: Exogenous Entry/Exit Rate}

In this subsection, we consider a special case in which firm entry and exit are exogenous. A new firm produces exactly the same goods as does an exiting firm; that is, $q(j, k)=1$ (thus, no growth). In so doing, we aim to illustrate that having firm entry and exit generates a real effect of money even in an otherwise simple menu cost model.

Caplin and Spulber (1987) show that money is neutral in a simple menu cost model. This result stems from endogenous changes in an extensive margin (frequency effect); that is, a change occurs in the fraction of firms that adjust their prices. Monetary policy shocks increase the fraction of such firms, adjusting the aggregate price level accordingly and completely offsetting the real effect. ${ }^{6}$

By adding just one flavor to the simple menu cost model, that is, firm entry and exit, we can show that money is no longer neutral. The key to this result is the non-uniform firm's price distribution. The fraction of marginal firms that are about to change their prices is lower than that of the sum of firms that just reset their prices and those that just enter the market. This dampens the extensive margin effect, and the real effect of money increases as the firm entry and exit rates increase.

Following Caplin and Spulber (1987), we start with the economy in which no aggregate uncertainty such as monetary policy is present. Money grows at the constant rate of $g>0$. After solving the stationary equilibrium of the economy, we then consider what happens when a monetary policy shock $\varepsilon^{M}$ occurs unexpectedly.

Household The setup for the representative household is the same as before, except that $q_{t}(j)=1$ for any $j$ and $t$.

Firm Profits Given equation (6) and

$$
C_{t}=\left[\int_{0}^{1} x_{t}(j)^{\frac{\theta-1}{\theta}} d j\right]^{\frac{\theta}{\theta-1}},
$$

\footnotetext{
${ }^{6}$ According to Golosov and Lucas (2007), the neutrality of money in Caplin and Spulber (1987) stems from a selection effect. The firms that revise their prices are not selected at random but are the ones whose prices are farthest from their reset prices. This increases the size of price changes, and in turn, the aggregate price in response to a monetary easing shock. Such an effect is relaxed in our model because the prices of exiting firms are not necessarily farthest from their reset prices.
} 
the demand for good $j$ can be described as

$$
x_{t}(j)=\left(\frac{p_{t}(j)}{P_{t}}\right)^{-\theta} \frac{M_{t}}{P_{t}}
$$

From equation (18), we can write the real period profits of firm $j$ as

$$
\frac{p_{t}(j)-W_{t}}{P_{t}}\left(\frac{p_{t}(j)}{P_{t}}\right)^{-\theta} \frac{M_{t}}{P_{t}} .
$$

We define the real price of each good, $\xi_{t}(j)$, and the real profit per unit of demand, $\Pi(\xi)$, such as

$$
\begin{aligned}
\xi_{t}(j) & \equiv \frac{p_{t}(j)}{W_{t}} \\
\Pi(\xi) & \equiv \frac{\xi-1}{\xi}(\chi m \xi)^{1-\theta}
\end{aligned}
$$

where $m_{t}$ represents $M_{t} / P_{t}$, which stays constant at $m$ in a stationary equilibrium of the economy. Then, from equation (8), the real period profit in the stationary state can be represented by $\Pi\left(\xi_{t}(j)\right) m$, following equations (19) and (21).

Pricing under Menu Cost Because we assume no quality gap between incumbents and entrants, no limit price exists in this simplified model. Thus, if $\theta \leq 1$, a firm sets its initial price at infinity and never resets it regardless of whether nominal rigidity exists or not. Hence we consider the case with $\theta>1$ in this subsection. If we introduce step size $q>1$, the main result of this subsection holds for any $\theta \geq 0 .^{7}$

Without nominal rigidity, equation (19) suggests that the optimal real price satisfies $\Pi^{\prime}\left(\xi^{*}\right)=0$ at $\xi^{*}=\theta /(\theta-1)$. With nominal rigidity, the firm prices remain unchanged, unless the firms pay menu cost in the form of $\kappa / \chi$ units of labor. Since $W_{t}$ is linear in $M_{t}$, equation (20) implies that the real price $\xi_{t}$ changes at the rate of $-g$. In other words, these goods become cheaper as time passes if $g>0$. In period $t_{i+1}$ for $i=0,1,2, \cdots$, they pay the menu cost and reset their price to $p_{i+1}$. The expected real present value of firm $v_{t}$ becomes

$$
v_{t}=\sum_{i=0}^{\infty}\left(\int_{t_{i}}^{t_{i+1}} \Pi\left(p_{i} e^{-g t^{\prime}}\right) e^{-(\rho+\mu) t^{\prime}} d t^{\prime}-\kappa e^{-(\rho+\mu) t_{i+1}}\right) .
$$

\footnotetext{
${ }^{7}$ Oikawa and Ueda (2015) analyze the pricing rule with $q>1$ and the limit price for the case with $\theta=1$.
} 
The first-order conditions with respect to $t_{i}$ and $p_{i}$ yield, respectively

$$
\begin{aligned}
& \frac{\partial v_{t}}{\partial t_{i}}=0=\left[\Pi\left(p_{i-1} e^{-g t_{i}}\right)-\Pi\left(p_{i} e^{-g t_{i}}\right)+\kappa(\rho+\mu)\right] e^{-(\rho+\mu) t_{i}}, \\
& \frac{\partial v_{t}}{\partial p_{i}}=0=\int_{t_{i}}^{t_{i+1}} \Pi^{\prime}\left(p_{i} e^{-g t^{\prime}}\right) e^{-(\rho+\mu+g) t^{\prime}} d t^{\prime}
\end{aligned}
$$

We define $S \equiv \log \left(p_{i} e^{-g t_{i}}\right)$ and $\Delta \equiv t_{i}-t_{i-1}$, and they satisfy

$$
\begin{aligned}
& 0=\Pi\left(e^{s}\right)-\Pi\left(e^{S}\right)+\kappa(\rho+\mu), \\
& 0=\int_{s}^{S} \Pi^{\prime}\left(e^{z}\right) e^{\frac{\rho+\mu+g}{g} z} d z, \\
& s \equiv \log \left(p_{i} e^{-g\left(t_{i}+\Delta\right)}\right)=S-g \Delta .
\end{aligned}
$$

These conditions pin down $S, s$, and $\Delta$ as the functions of $g$ and $\mu$.

Firm Distribution Because of the presence of menu cost, firms are heterogeneous with respect to their prices. Log real prices $z \equiv \log \xi$ are distributed in the range between $s$ and $S$, or, in terms of the time following the last price change, in the range between 0 and $\Delta$. We denote the density function of $z\left(t^{\prime}\right)$ using $f\left(z\left(t^{\prime}\right)\right)$, where $t^{\prime} \in[0, \Delta]$ and $z \in[s, S]$. Because $z\left(t^{\prime}\right)$ changes at the rate of $-g$ for $z \in[s, S]$, the density function should satisfy

$$
\begin{aligned}
f\left(z\left(t^{\prime}\right)\right) & =f\left(z\left(t^{\prime}-d t^{\prime}\right)\right)\left(1-\mu d t^{\prime}\right) \\
& =f\left(z\left(t^{\prime}\right)+g d t^{\prime}\right)\left(1-\mu d t^{\prime}\right)
\end{aligned}
$$

for a small $d t^{\prime}$ if the firm distribution is stationary. This equation implies that the density at $t^{\prime}$ should be equal to that of $t^{\prime}-d t^{\prime}$ multiplied by the survival probability of firms between $t^{\prime}-d t^{\prime}$ and $d t^{\prime}$, that is, $1-\mu d t^{\prime}$. This equation is transformed into $d \log f\left(z\left(t^{\prime}\right)\right)=\mu / g$. Using $1=\int_{0}^{\Delta} f\left(z\left(t^{\prime}\right)\right) d t^{\prime}$, we obtain the following firm density function:

$$
f\left(z\left(t^{\prime}\right)\right)=\frac{\mu}{1-e^{-\mu \Delta}} e^{-\mu t^{\prime}}
$$

That is, firm distribution is not uniform. Its density function is decreasing with respect to $t^{\prime}$ and increasing with respect to the real price $\xi$. 


\subsubsection{The Aggregate Inflation Rate}

Since the price level is depicted as

$$
P_{t}=\left(\int_{0}^{1} p_{t}(j)^{1-\theta} d j\right)^{\frac{1}{1-\theta}}
$$

the aggregate inflation rate can be written as

$$
\begin{aligned}
g d t & =\log P_{t+d t}-\log P_{t} \\
& =f(z(\Delta)) d t \cdot(S-s)+\mu d t \cdot S .
\end{aligned}
$$

The left-hand side is $g d t$ because $M_{t} / P_{t}$ stays constant in the stationary equilibrium of the economy and $M_{t}$ grows at the rate of $g$. The right-hand side is derived through the following two channels. First, firms change their log real prices from $s$ to $S$ by paying the menu cost with probability $f(z(\Delta)) d t$. Second, new firms enter the market with probability $\mu d t$. A new $\log$ real price is set at $S$ from the average log price of zero. Thus, we have

$$
g=\frac{\mu}{1-e^{-\mu \Delta}} e^{-\mu \Delta} g \Delta+\mu S
$$

\subsubsection{Real Effect of a Monetary Policy Shock}

Thus far, we assumed no aggregate uncertainty. To consider the real effect of monetary policy shock, we now assume that a monetary policy shock $\varepsilon_{t}^{M}$ occurs unexpectedly in period $t$ as

$$
\log \left(M_{t} / M_{t-1}\right)=g_{t}=g+\varepsilon_{t}^{M}
$$

Prior to period $t$, the economy is at a stationary equilibrium. The size of a monetary policy shock is sufficiently small compared to $g$. When a shock occurs, the real money stock, $m$, may change, but as in Caplin and Spulber (1987), we assume that it remains unchanged. Thus, $S$, $s$, and $\Delta$ do not change. As long as the monetary policy shock is temporary and small, this assumption does not appear to be restrictive.

As equation (19) shows, the nominal marginal cost increases by the growth rate of money. A surprise monetary policy shock thus further lowers the real prices $\xi_{t}(j)$ by $\varepsilon_{t}^{M} d t$. Therefore, the firms that reset their prices $t^{\prime} \in\left[\Delta-d t-\varepsilon_{t}^{M} d t / g, \Delta\right]$ periods ago reset their prices between 
periods $t$ and $t+d t$. The inflation rate thus becomes

$$
\begin{aligned}
\pi_{t} d t & =\log P_{t+d t}-\log P_{t} \\
& =\int_{\Delta-d t-\varepsilon^{M} d t / g}^{\Delta} f\left(z\left(t^{\prime}\right)\right) d t^{\prime} \cdot(S-s)+\mu d t \cdot S,
\end{aligned}
$$

yielding

$$
\begin{aligned}
\pi_{t} & =\frac{1}{d t} \int_{\Delta-d t-\varepsilon_{t}^{M} d t / g}^{\Delta} \frac{\mu}{1-e^{-\mu \Delta}} e^{-\mu t^{\prime}} d t^{\prime} \cdot(S-s)+g-\frac{\mu e^{-\mu \Delta}}{1-e^{-\mu \Delta}} g \Delta \\
& =\frac{\mu e^{-\mu \Delta}}{1-e^{-\mu \Delta}}\left(1+\frac{\varepsilon_{t}^{M}}{g}\right) g \Delta+g-\frac{\mu e^{-\mu \Delta}}{1-e^{-\mu \Delta}} g \Delta \\
& =g+\frac{\mu \Delta e^{-\mu \Delta}}{1-e^{-\mu \Delta}} \varepsilon_{t}^{M} .
\end{aligned}
$$

From equation (6), consumption changes as

$$
\begin{aligned}
d \log C_{t} & =g+\varepsilon_{t}^{M}-\pi_{t} \\
& =\left(1-\frac{\mu \Delta e^{-\mu \Delta}}{1-e^{-\mu \Delta}}\right) \varepsilon_{t}^{M} .
\end{aligned}
$$

Since the coefficient on $\varepsilon_{t}^{M}$ is positive, a positive monetary policy shock increases consumption.

Proposition 1 Money is not neutral unless the entry and exit rate $\mu$ is zero. For $\mu \ll 1$, the real effects of money increase as $\mu$ increases.

The proof of the first sentence has already been provided previously. For the second sentence, we know that $d(\mu \Delta) / d \mu=\Delta+\mu(d \Delta / d \mu)$ and $d \Delta / d \mu$ is finite. ${ }^{8}$ Thus, for a sufficiently small $\mu, d(\mu \Delta) / d \mu$ is positive. For $x>0$, the function $f(x)=1-\frac{x e^{-x}}{1-e^{-x}}$ is positive and increasing with $x$. Thus, the coefficient on $\varepsilon_{t}^{M}$ in equation (31) is increasing with $\mu$ for $\mu \ll 1$.

This proposition suggests that the monetary policy shock is not completely canceled out by a change in price level. This contrasts the result reported by Caplin and Spulber (1987). In their model, no firm entry or exit is present and hence firm distribution is uniform. Thus, the density of firms whose real price is close to $S$ is the same as that of firms whose real price is close to $s$. In our model, because firms enter and exit, firm distribution is no longer uniform.

$$
\begin{aligned}
& { }^{8} \text { From equations (24) to (26), we obtain } \\
& \frac{d \Delta}{d \mu}=-\frac{1}{g}\left[1+\frac{\frac{\Pi^{\prime}\left(e^{S}\right)}{\Pi^{\prime}\left(e^{s}\right)} e^{\left(1+\frac{\rho+\mu}{g}\right) g \Delta}-1}{\frac{\Pi^{\prime}\left(e^{S}\right)}{\Pi^{\prime}\left(e^{s}\right)} e^{g \Delta}-1}\right]^{-1}\left[\frac{\frac{\Pi^{\prime}\left(e^{S}\right)}{\Pi^{\prime}\left(e^{s}\right)} e^{\left(1+\frac{\rho+\mu}{g}\right) g \Delta}-1}{\frac{\Pi^{\prime}\left(e^{S}\right)}{\Pi^{\prime}\left(e^{s}\right)} e^{g \Delta}-1} \frac{\kappa}{\Pi^{\prime}\left(e^{s}\right) e^{s}}+\frac{\int_{s}^{S} \Pi^{\prime}\left(e^{z}\right) z e^{\left(1+\frac{\rho+\mu}{g}\right) z} d z}{\Pi^{\prime}\left(e^{s}\right) e^{\left(1+\frac{\rho+\mu}{g}\right) s}}\right] .
\end{aligned}
$$

Since $\Pi^{\prime}\left(e^{s}\right)>0>\Pi^{\prime}\left(e^{S}\right)$, this is finite as long as $g \neq 0$. 
Over time, an increasing number of firms exit, and the density of firms whose real price is close to $S$ becomes larger than that of firms whose real price is close to $s$. A monetary policy shock induces the latter firms to reset their prices. Because their density is relatively low, the change in the extensive margin and that in the aggregate price level are small. This generates the real effects of monetary policy.

\subsection{Simple Case 2: Constant Money Growth}

In this subsection, we develop a model of endogenous creative destruction rate. To focus on the long-run growth impact of monetary shock, we assume that $\theta=1$, constant $q>1$, and nonstochastic $g$.

When $\theta=1$, equation (3) suggests that the demand for goods is given by

$$
x_{t}(j, k)=\frac{M_{t}}{p_{t}(j, k)}
$$

for the highest version $k=K_{t}(j)$ and zero otherwise unless the posted price is too high. When only the highest version of products exist in the markets, the aggregate price $P_{t}$ can be written as

$$
\log P_{t}=\int_{0}^{1} \log \left[\frac{p_{t}\left(j, K_{t}(j)\right)}{\tilde{q}\left(j, K_{t}(j)\right)}\right] d j
$$

with quality improvement taken into account.

From equation (32), we can write the period profit of industry-leading firms with $k=K_{t}(j)$ as

$$
\Pi_{t}\left(p_{t}(j, k)\right)=\frac{p_{t}(j, k)-W_{t}}{p_{t}(j, k)} \frac{M_{t}}{P_{t}}=\frac{\xi_{t}(j, k)-1}{\xi_{t}(j, k)} \frac{M_{t}}{P_{t}} \equiv \Pi\left(\xi_{t}(j, k)\right) \frac{M_{t}}{P_{t}}
$$

in real terms. Owing to competition with rival firms, the firm profit becomes zero unless

$$
p_{t}(j, k) \leq q W_{t}=q \chi M_{t}
$$

Thus, this constitutes a limit price, $\xi_{t}=q$.

The real value of the entering firm, $v_{t}^{E}$, is

$$
\begin{aligned}
v_{t}^{E} & =\frac{P_{t}}{M_{t}} \max _{\left\{t_{i}, p_{i}\right\}} \sum_{i=0}^{\infty}\left[\int_{t_{i}}^{t_{i+1}} \Pi_{t^{\prime}}\left(p_{i} e^{-g t^{\prime}}\right) e^{-(r+\mu)\left(t^{\prime}-t\right)} d t^{\prime}-\kappa \frac{M_{t_{i+1}}}{P_{t_{i+1}}} e^{-(r+\mu)\left(t_{i+1}-t\right)}\right] \\
& =\max _{\Delta} \frac{1}{1-e^{-(\rho+\mu) \Delta}}\left[\int_{0}^{\Delta} \Pi\left(\xi e^{-g t^{\prime}}\right) e^{-(\rho+\mu) t^{\prime}} d t^{\prime}-\kappa e^{-(\rho+\mu) \Delta}\right],
\end{aligned}
$$

where $\xi$ is the reset relative price: $\xi=q$ if $g \geq 0$ and $\xi=q e^{g \Delta}$ for $g<0$. Following Oikawa 
and Ueda (2015), we obtain

$$
v_{t}^{E}=\left\{\begin{array}{lr}
\frac{1}{\rho+\mu}\left(1-\frac{e^{g \Delta(g, \mu)}}{q}\right)+\kappa & \text { for } g>0 \\
\frac{1}{\rho+\mu}\left(1-\frac{e^{-g \Delta(g, \mu)}}{q}\right) & \text { for } g<0 .
\end{array}\right.
$$

At the same time, the free-entry and the household's labor supply optimality conditions, (1) and (8), require

$$
v_{t}^{E}=\chi h
$$

as long as $\mu>0$. Equations (37) and (38) pin down the long-run $\mu$ in response to the money growth rate $g$.

Proposition 2 The frequency of creative destruction, $\mu$, is decreasing in $|g|$.

The proof of this proposition is straightforward from Lemma 2 in Oikawa and Ueda (2015), which states that

$$
\left.\frac{d v^{E}}{d|g|}\right|_{d \mu=0}<0,\left.\quad \frac{d v^{E}}{d \mu}\right|_{d g=0}<0 \quad \text { if } g \neq 0 \text { and } \mu>0 .
$$

To keep $v_{t}^{E}$ constant, a greater $|g|$ leads to a smaller $\mu$.

This proposition indicates us that a permanent monetary shock is not super-neutral. It has a negative impact on the real growth rate, because the real growth is monotonically increasing in frequency of innovation, $a=\mu \log q$, as in standard quality ladder models. A transitory shock affects the real growth rate temporarily but a level effect remains in the long run.

The intuition behind this result is simple. Focus on the case $g \geq 0$ for convenience. When $g=0$, there is no need to reset the price $(\Delta=\infty)$ and no menu cost payment. As $g$ becomes larger, firms would incur more menu cost payments owing to more frequent price changes, leading to a decline in $v_{t}^{E}$. Now, potential entrants have less incentive to innovate, and the entry rate in the aggregate economy, $\mu$, becomes smaller, which, in turn, increases $v_{t}^{E}$ until $v_{t}^{E}$ is equalized to the constant labor cost.

The two simplified models in this section illustrate the short-run positive and long-run negative effects of monetary easing. An increase in $g$ raises the real consumption under nominal rigidity, but at the same time, deteriorates firm value by more frequent menu cost payments that discourages R\&D by potential entrants. This tradeoff motivates us to investigate which impact dominates under a plausible parameter setting. 


\section{Model with Endogenous Firm Entry and Shocks}

We now return to the model in Section 2 and examine its equilibrium numerically. We assume the unit elasticity of substitution between products, $\theta=1$, unlike previous studies such as Golosov and Lucas (2007), Nakamura and Steinsson (2010), and Midrigan (2011). ${ }^{9}$ As will be clear, this assumption simplifies the numerical simulation of our model greatly.

\subsection{Values of Industry-leading Firms}

Substituting (8) and (20), the value functions of the firms can be simplified to

$$
\begin{aligned}
v_{t}^{R}\left(q_{t}(j), \Omega_{t-1}, g_{t}\right)=\max _{\xi}\left[\frac{\xi-1}{\xi}-\kappa+\beta \mathbb{E}_{t}^{j}\left[\left(1-\mu_{t+1}\right) v_{t+1}\left(\xi e^{-g_{t+1}}, q_{t}(j), \Omega_{t}, g_{t+1}\right)\right]\right] \\
\begin{aligned}
v_{t}^{N}\left(\xi_{t-1}(j) e^{-g_{t}}, q_{t}(j), \Omega_{t-1}, g_{t}\right) & =\frac{\xi_{t-1}(j) e^{-g_{t}}-1}{\xi_{t-1}(j) e^{-g_{t}}} \\
& +\beta \mathbb{E}_{t}^{j}\left[\left(1-\mu_{t+1}\right) v_{t+1}\left(\xi_{t-1}(j) e^{-g_{t}-g_{t+1}}, q_{t}(j), \Omega_{t}, g_{t+1}\right)\right] .
\end{aligned}
\end{aligned}
$$

We need condition (35) with $q_{t}(j)$ instead of constant $q$, or, equivalently,

$$
1 \leq \xi_{t}(j) \leq q_{t}(j)
$$

to earn a positive profit in period $t$. If the leading firm's real price is higher than $q_{t}(j)$, we assume that this firm stops production and its competitive firm with lower $\tilde{q}$ produces goods and sells them for $\xi_{t}(j)=1$. The firm value at entry equals

$$
v_{t}^{E}\left(\Omega_{t-1}, g_{t}\right)=\mathbb{E}_{t} \max _{\xi}\left[\frac{\xi-1}{\xi}+\beta\left(1-\mu_{t+1}\right) v_{t+1}\left(\xi e^{-g_{t+1}}, q, \Omega_{t}, g_{t+1}\right)\right]
$$

where we again assume that the probability of $q \leq 1$ is negligible.

Note that these firm values are independent of firm distribution $\Omega_{t-1}$. Except for $\mu_{t}$, there is no term in equations (39) to (42) explicitly depends on $\Omega_{t-1}$. Moreover, $\mu_{t}$ is independent of $\Omega_{t-1}$, too, because it is determined by $v_{t}^{E}=\chi h$ from equations (1) and (8). Therefore, unlike Nakamura and Steinsson (2010) and Midrigan (2011), we do not have to adopt an approximation method, as developed by Krusell and Smith (1998). This property arises partly because the elasticity of substitution between products is 1 . Otherwise, an aggregate price level $P_{t}$ would enter into period profits, like in equation (21), through which $\Omega_{t-1}$ influences firm values.

\footnotetext{
${ }^{9}$ Lentz and Mortensen (2008) calibrate $\theta=1$ in a model with creative destruction.
} 
In summary, we obtain

$$
\begin{aligned}
& v_{t}=\max \left(v_{t}^{R}, v_{t}^{N}\right), \\
& v_{t}^{R}\left(q_{t}(j), g_{t}\right)=\max _{\xi}\left[\frac{\xi-1}{\xi}-\kappa+\beta\left(1-\mu_{t+1}\left(g_{t}\right)\right) \mathbb{E}_{t}^{j}\left[v_{t+1}\left(\xi e^{-g_{t+1}}, q_{t}(j), g_{t+1}\right)\right]\right], \\
& v_{t}^{N}\left(\xi_{t-1}(j) e^{-g_{t}}, q_{t}(j), g_{t}\right) \\
& =\frac{\xi_{t-1}(j) e^{-g_{t}}-1}{\xi_{t-1}(j) e^{-g_{t}}}+\beta\left(1-\mu_{t+1}\left(g_{t}\right)\right) \mathbb{E}_{t}^{j}\left[v_{t+1}\left(\xi_{t-1}(j) e^{-g_{t}-g_{t+1}}, q_{t}(j), g_{t+1}\right)\right], \\
& v_{t}^{E}\left(g_{t}\right)=\mathbb{E}_{t} \max _{\xi}\left[\frac{\xi-1}{\xi}+\beta\left(1-\mu_{t+1}\left(g_{t}\right)\right) v_{t+1}\left(\xi e^{-g_{t+1}}, q, g_{t+1}\right)\right] \text {. }
\end{aligned}
$$

Note that $\mu_{t+1}$ depends on expected $g_{t+1}$ not realized $g_{t+1}$, because $\mu_{t+1}$ is determined by equation (46). Thus, $\mu_{t+1}$ is a function of $g_{t}$.

The firm value at entry, $v_{t}^{E}$, is constant, from equations (1) and (8). Thus, equation (46) determines $\mu_{t+1}$, given $v_{t+1}$. Consider what happens when the money supply growth rate, $g_{t}$, increases. Assume a persistent money shock so that $g_{t+1}$ increases, too. First, it increases consumption, $M_{t} / P_{t}=C_{t}$, because firm distribution is non-uniform and price increases are less than money increases, as illustrated in Section 3.1. Second, analogous to the argument in Section 3.2, $v_{t+1}$ decreases because the menu cost payment increases. Thus, $\mu_{t+1}$ falls to keep $v_{t+1}^{E}$ constant. This implies a lower growth rate of consumption. In this way, a tradeoff between the short-run increase and long-run decrease is generated.

The policy function of firm $j$ can be obtained from equations (44) and (45) as

$$
\xi_{t}(j)=F\left(\xi_{t-1}(j) e^{-g_{t}}, q_{t}(j), g_{t}\right)
$$

For convenience, we give the real price set by entering firm $j$ as

$$
\xi_{t}^{*}(j)=F\left(\infty, q_{t}(j), g_{t}\right)
$$

Note that $F\left(\xi_{t-1}(j) e^{-g_{t}}, q_{t}(j), g_{t}\right)$ equals $\xi_{t-1}(j) e^{-g_{t}}$ if $v_{t}^{R} \leq v_{t}^{N}$, and $\xi_{t}^{*}(j)$ otherwise. Since entering firm $j$ sets its price after observing $q_{t}(j)$, the optimal price is the same between entrants and price-resetting incumbents, given $q_{t}(j)$. 


\subsection{Firm Distribution}

The density function of firms, $\Omega_{t}$, is a function of $\xi_{t}, q_{t}$, and $g_{t}$ and its law of motion is described as

$$
\begin{aligned}
& \Omega_{t}\left(\xi_{t}, q_{t}, g_{t}\right) \\
& =\int d g_{t-1} \int d \xi_{t-1} I_{\left\{\xi_{t-1} \mid \xi_{t}=F\left(\xi_{t-1} e^{\left.\left.-g_{t}, q_{t}, g_{t}\right)\right\}}\right.\right.} \operatorname{Pr}\left(g_{t} \mid g_{t-1}\right)\left(1-\mu_{t}\left(g_{t-1}\right)\right) \Omega_{t-1}\left(\xi_{t-1}, q_{t}, g_{t-1}\right) \\
& \quad+\int d g_{t-1} I_{\left\{\xi_{t}=F\left(\infty, q_{t}, g_{t}\right)\right\}} \operatorname{Pr}\left(g_{t} \mid g_{t-1}\right) \operatorname{Pr}\left(q_{t}\right) \mu_{t}\left(g_{t-1}\right) \operatorname{Pr}\left(g_{t-1}\right),
\end{aligned}
$$

from which we can compute the stationary density function $\Omega(\xi, q, g)$.

The density function given the history of $g_{t}, g^{t}=\left\{g_{t}, g_{t-1}, g_{t-2}, \cdots\right\}$, that is, $\Gamma_{t}$, is described as

$$
\begin{aligned}
\Gamma_{t}\left(\xi_{t}, q_{t} \mid g^{t}\right)=(1 & \left.-\mu_{t}\left(g_{t-1}\right)\right) \int d \xi_{t-1} I_{\left\{\xi_{t-1} \mid \xi_{t}=F\left(\xi_{t-1} e^{\left.\left.-g_{t}, q_{t}, g_{t}\right)\right\}}\right.\right.} \Gamma_{t-1}\left(\xi_{t-1}, q_{t} \mid g^{t-1}\right) \\
& +\mu_{t}\left(g_{t-1}\right) I_{\left\{\xi_{t}=F\left(\infty, q_{t}, g_{t}\right)\right\}} \operatorname{Pr}\left(q_{t}\right) .
\end{aligned}
$$

We assume that, in the initial period of $t=0, g_{t=0}$ equals $g$ and the density function is its stationary one:

$$
\Gamma_{0}\left(\xi, q \mid g^{0}\right)=\Gamma(\xi, q)=\int d g \Omega(\xi, q, g) .
$$

\subsection{The Aggregate Inflation Rate}

We analyze the growth rate of the aggregate price index. Equation (33) is transformed into

$$
\begin{aligned}
\pi_{t} & =\log P_{t}-\log P_{t-1} \\
& =\int_{0}^{1} \log \left[\frac{p_{t}\left(j, K_{t}(j)\right)}{\tilde{q}\left(j, K_{t}(j)\right)}\right] d j-\int_{0}^{1} \log \left[\frac{p_{t-1}\left(j, K_{t-1}(j)\right)}{\tilde{q}\left(j, K_{t-1}(j)\right)}\right] d j .
\end{aligned}
$$

This yields the inflation rate given $g^{t}$ :

$$
\begin{aligned}
\pi_{t}= & \left(1-\mu_{t}\left(g_{t-1}\right)\right) \int d \xi_{t-1} \int d q \cdot \Gamma_{t-1} \cdot \log \left(\frac{F\left(\xi_{t-1} e^{-g_{t}}, q, g_{t}\right)}{\xi_{t-1} e^{-g_{t}}}\right) \\
& +\mu_{t}\left(g_{t-1}\right)\left(\int d \Omega_{q} \cdot \log \left(\frac{F\left(\infty, q, g_{t}\right)}{q e^{-g_{t}}}\right)-\int d \xi_{t-1} \int d q \cdot \Gamma_{t-1} \cdot \log \xi_{t-1}\right),
\end{aligned}
$$

where $\Omega_{q}$ is the marginal distribution about $q .{ }^{10}$

\footnotetext{
${ }^{10} \Omega_{q}$ is equivalent to the exogenous distribution of $q$, from which entrants draw, if its support lies above 1.
} 
The real growth rate denoted by $a_{t}$ is given by

$$
a_{t}=\log \left(\frac{C_{t}}{C_{t-1}}\right)=\log \left(\frac{M_{t} / P_{t}}{M_{t-1} / P_{t-1}}\right)=g_{t}-\pi_{t}
$$

Note that, in the deterministic case where neither a quality nor monetary policy shock exists, equations (53) and (54) are simplified to $a=\mu \log q$. This suggests that the real growth rate is the highest when $\mu$ is the highest.

Since the entry rate $\mu$ in equilibrium could be lower or higher than the socially optimal level, a higher growth rate is not necessarily better in terms of welfare in general. However, our calibrated parameters in Section 5 indicate that it is plausible to think it is actually better in terms of welfare, in other words, $\mathrm{R} \& \mathrm{D}$ is underinvested in the market equilibrium (satisfying the following condition (55)).

In the special case of $\theta=1$, the market equilibrium is associated with underinvestment in $\mathrm{R} \& \mathrm{D}($ too low $\mu$ ) if

$$
\log \bar{q}>\frac{1-\beta}{\beta h \chi} .
$$

One can find this condition by solving the social planner's problem, in its simplified form,

$$
\max \sum_{t=0}^{\infty} \beta^{t}\left[\mathcal{K}_{t} \log \bar{q}+\log x_{t}-\chi\left(h\left(\mathcal{K}_{t+1}-\mathcal{K}_{t}\right)+x_{t}\right)\right]
$$

where $\bar{q}$ is the average step size of new innovation, $\mathcal{K}_{t} \equiv \int_{0}^{1} K_{t}(j) d j$ and $x_{t}(j)=x_{t}$ for all $j .{ }^{11}$

\subsection{Equilibrium}

An equilibrium is a collection of prices and allocations, $\xi_{t}(j), P_{t}, C_{t}$, and $\mu_{t}$ such that, taking prices as given, the allocations and prices solve the household's and firm's problems and the goods and labor markets clear, given the exogenous shocks $\varepsilon_{t}^{M}$ and $q(j)$. Specifically, an equilibrium of the model economy consists of 12 values and functions: $v_{t}^{E}, v_{t}^{R}, v_{t}^{N}, v_{t}, F, g_{t}, W_{t} / P_{t}$, $M_{t} / P_{t}, C_{t}, \pi_{t}, \mu_{t}$, and $\Omega_{t}$; they satisfy 12 equations: (1), (6), (8), (16), (43), (44), (45), (46), (47), (49), (52), and (53).

We make the following iterative steps to solve for the equilibrium: ${ }^{12}$ (i) We specify a finite grid of points for the state variables, $\xi_{t}(j), q_{t}(j)$, and $g_{t}$. (ii) We solve for the firm's policy function $F$ by value function iteration using equations (43), (44), and (45), where we use $\mu_{t+1}\left(g_{t}\right)$ obtained in the previous iteration and we update $\mu_{t+1}\left(g_{t}\right)$ using equations $(1)$ and (46). This enables us to obtain $v_{t}^{E}, v_{t}^{R}, v_{t}^{N}, v_{t}, F$, and $\mu_{t}$. (iii) We calculate other features of

\footnotetext{
${ }^{11}$ When $\theta \neq 1$, whether R\&D is under- or over-invested depends on the level of the equilibrium entry rate.

${ }^{12}$ The code we used is based on that in Nakamura and Steinsson $(2008,2010)$.
} 
the equilibrium values such as $M_{t} / P_{t}, C_{t}, \pi_{t}$, and $\Omega_{t}$.

\section{Monetary Policy Effects}

\subsection{Calibration}

Our model is calibrated to the U.S. economy. The unit of time interval is week. The number of grids is 101,500 , and 21 for $\xi_{t}(j), q_{t}(j)$, and $g_{t}$, respectively. Table 1 shows the summarized parameter values and moments, respectively. We set $\beta=0.96$ in an annual basis. The per-capita GDP growth during the period 1995 to 2012 implies that the average per-capita GDP growth rate is $a=0.0127$ in real terms and $g=0.0328$ in nominal terms annually. The parameters associated with monetary policy, $\rho$ and $\sigma_{M}$, are respectively 0.41 and 0.027 quarterly, which are then transformed into weekly basis, in the same way as Midrigan (2011). The entry and exit rate of firms (product substitution rate) $\mu$ is 0.034 monthly according to Bils and Klenow (2004). ${ }^{13}$ According to Nakamura and Steinsson (2008), the monthly frequency of price changes is 0.087 excluding product substitution. This amounts to 0.022 in weekly terms if the firms are homogeneous in pricing decisions. If firms are heterogeneous, and this is actually true according to Bils and Klenow (2004) and Nakamura and Steinsson (2008), then the actual weekly frequency of price changes is considered to be between 0.022 and $0.087 .^{14}$

Using the above values, we calibrate $\chi, h, \bar{q}, \sigma_{q}$, and $\kappa$, assuming that $q_{t}(j)$ obeys normal distribution with mean $\bar{q}$ and standard deviation $\sigma_{q}$. We calibrate $\chi$ to match $L$ and calibrate $h$ and $\bar{q}$ to match $a$ and $\mu$. Since we do not have good prior information, we set $\sigma_{q}=0.005$ tentatively, but we confirm that this choice does not alter our results below. As for the size of menu cost, we set $\kappa=0.05$, which is several times larger than that in previous studies: 0.007 in Levy et al. (1997) and 0.022 in Midrigan (2011). Even with this relatively large value, our model yields a frequency of price changes (excluding product substitution) four times as high as the lowest bound of the actual frequency, that is, 0.022 weekly. ${ }^{15}$

In our model, two features lead to a higher frequency of price changes. The first is Bertrand competition within product lines. If there were no Bertrand competition, the Ss band of real prices would be constructed around the "optimal" price in equation (12), depending on the

\footnotetext{
${ }^{13}$ The average of entry and exit rates of establishments is 0.118 annually, which is lower than the rate of product substitution.

${ }^{14}$ The weekly frequency of price changes equals its upper bound, for example, in the following case. Two types of goods (A and B) exist and differ in the frequency of price changes. The share of A is 0.087 and that of $\mathrm{B}$ is 0.913 . The weekly frequency of price changes is one for A and zero for B. This means that the monthly frequency of price changes is also one for A and zero for B. Thus, the weighted average of the frequency of price changes equals 0.087 both weekly and monthly.

${ }^{15}$ Here, we assume that prices are not revised when the industry-leading firm gives up production and stops price revision and the second-best firm instead produces at the $\xi=1$.
} 
stochastic process of $g_{t}$. For example, if $g_{t}$ is symmetric around zero, the optimal price should be about the center of the Ss band. Bertrand competition brings a discontinuous cutoff on the profit and allows narrower (or no) space of prices higher than the optimal one. Thus, firms tend to have lower $S$. Because of concavity of the profit curve for prices lower than the optimal price, the marginal benefit of revising prices tends to be larger than that without the limit price if the width of the Ss band is the same. This implies that they have more incentive to reset their price. This is definitely significant if $\theta \leq 1$ because it implies that real profit is monotonically increasing and the optimal price is never available for firms owing to the limit price.

Second, like Golosov and Lucas (2007), Nakamura and Steinsson (2010), and Midrigan (2011), introducing one more type of shock that captures technological changes may lower the size of menu cost. If productivity changes every period, firms come to have more incentive to wait and see their output prices, which could lower the frequency of price changes. However, this remedy may not necessarily increase price stickiness because firms are subject to larger shocks. Moreover, it increases the dimension of state variables to four, which definitely complicates our analysis further.

Admitting these challenges, we choose $\kappa=0.05$ so as to obtain a weekly frequency of price changes close to the highest bound of the actual frequency, 0.087, in Nakamura and Steinsson (2008). With regards the size of price changes, our model yields much lower values than actual data, probably reflecting the above challenge that our model yields a higher frequency of price changes.

\subsection{Deterministic Case}

For illustration, we begin with a deterministic model in which there is no aggregate monetary policy shock. This is essentially the same as the model in Section 3.2. Figure 1 illustrates how a deterministic change in money growth rate $g$ influences the equilibrium. The rates of change are displayed on an annual basis. The real growth rate $a$ is the highest when $g$ is zero. The inflation rate $\pi=g-a$ exhibits a kink at $g=0$. These results are in line with our earlier findings in Oikawa and Ueda (2015). An important implication is that permanent monetary easing (too high $g$ ) lowers the entry-exit rate, and, in turn, the real economic growth rate.

The circles in graphs indicate the points calibrated using a stochastic model in which monetary policy shock is present. For both $a$ and $\mu$, the circles lie almost on the curve. That is, the real growth rate and the entry-exit rate hardly change in the stochastic environment compared with those in the deterministic one. 
Table 1: Calibration

\begin{tabular}{ccccc}
\multicolumn{2}{c}{ Calibrated parameters } & & \multicolumn{2}{c}{ Assigned parameters } \\
\cline { 1 - 2 } $\bar{q}$ & 2.1647 & & $\beta$ & $0.96^{1 / 52}$ \\
$\chi$ & 1.0286 & & $g$ & $1.0328^{1 / 52}-1=6.20 \cdot 10^{-4}$ \\
$\kappa$ & 0.9983 & & $\rho$ & $0.40476^{1 / 13}=0.9328$ \\
& 0.05 & & $\sigma_{M}$ & $3.11 \cdot 10^{-4}$ \\
& & $\sigma_{q}$ & 0.005
\end{tabular}

\begin{tabular}{ccc} 
Moments & Data & $\begin{array}{c}\text { Stochastic model } \\
\text { (benchmark) }\end{array}$ \\
\hline Real growth rate $a$ & $\begin{array}{c}1.0127^{1 / 52}-1 \\
=2.43 \cdot 10^{-4} \\
1-(1-0.034)^{1 / 4}\end{array}$ & $2.29 \cdot 10^{-4}$ \\
Entry-exit rate $\mu$ & $0.022 \sim 0.087$ & $8.37 \cdot 10^{-3}$ \\
Frequency of price changes & $0.028 \sim 0.109$ & 0.083 \\
$\begin{array}{c}\text { Frequency of price changes } \\
\text { including product substitution } \\
\text { Size of price changes } \\
\text { Size of price changes }\end{array}$ & 0.085 & 0.090 \\
when product substitution & - & 0.009
\end{tabular}
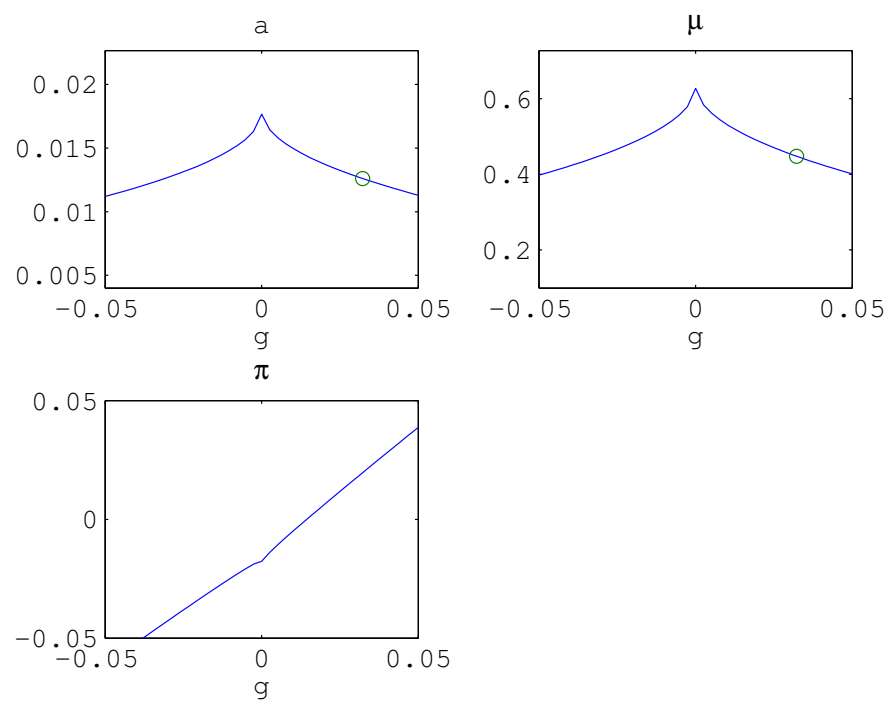

Figure 1: Quantitative impacts of money growth. The circles in graphs indicate the points calibrated using the stochastic model. 


\subsection{Stochastic Case}

\subsubsection{Equilibrium and Stationary Distribution}

In this subsection, we present an equilibrium in a stochastic environment. Figure 2 displays the key variables, where the rates of change are displayed on an annual basis.

The top right panel displays the policy function $F\left(\xi_{t}(j), q_{t}(j), g_{t}\right)$ with $g_{t}$ on the horizontal axis, where $q_{t}(j)$ is set at its mean $\bar{q}$. The three lines are depicted in the order of the upper bound of no price change $(S)$, the reset price $\left(\xi_{t}^{*}(j)\right)$, and the lower bound of no price change $(s)$ from the top. As $g_{t}$ moves away from its mean $g$, the Ss band is widened. That is, given $\xi_{t}(j)$, firms tend not to revise their prices, because $\xi_{t}(j)$ changes fast and the marginal benefit of revising their price decreases. When $g_{t}$ is positive, $\xi_{t}(j)$ declines over time as long as the posted prices remain unchanged. Thus, the reset price $\xi_{t}^{*}(j)$ equals the limit price, $q_{t}(j)$, which does not depend on $g_{t}$. When $\xi_{t}(j)$ decreases sufficiently low to the level of $s$, firms reset their prices at $\xi_{t}^{*}(j)$. Interestingly, firms do not necessarily revise their prices even though $\xi_{t}(j)$ surpasses $q_{t}(j)$ and their period profit falls to zero. This is because there is a positive probability that, after some period $i, \xi_{t+i}(j)$ falls below the limit price and the period profit becomes positive by having a high $g_{t}$. When $g_{t}$ is negative, $\xi_{t}(j)$ rises over time as long as the posted prices remain unchanged. Thus, firms reset their prices at a lower level than the limit price $q_{t}(j)$ and $\xi_{t}^{*}(j)$ decreases as $g_{t}$ decreases. In parallel, $s$ also decreases.

The top middle panel shows the policy function $F\left(\xi_{t}(j), q_{t}(j), g_{t}\right)$ with $\xi_{t}(j)$ on the horizontal axis for $q_{t}(j)=\bar{q}$ and $g_{t}=g$. When $\xi_{t}(j)$ goes too low, firms reset their prices by paying the menu cost. Firms may not reset their prices even though $\xi_{t}(j)$ exceeds $\bar{q}$ and their period profit is zero because of the above argument. Firms wait for a while.

As the top left panel shows, the rate of product substitution in period $t, \mu_{t}=\mu\left(g_{t-1}\right)$, has an inverse $\mathrm{U}$ shape with respect to $g_{t-1}$. The dotted vertical line is plotted at $g_{t-1}=g$. Note that here $g_{t-1}$ is the money supply growth rate not in the long-run, but in the previous period $t-1$. This shape resembles that in Figure 1 for a deterministic model, but differs in two points. First, $\mu_{t}$ is the highest not at $g_{t-1}=0$. Second, the curve is asymmetric. The slope of the decline in $\mu_{t}$ is larger for positive $g_{t-1}$ than for negative $g_{t-1}$. These reasons can be attributed to the presence of a limit price at $q_{t}(j)$. The profits of firms are discontinuous at $\xi_{t}(j)=q_{t}(j)$. On the one hand, their profits decrease gradually when $\xi_{t}(j)$ falls from $q_{t}(j)$, and drop to zero when $\xi_{t}(j)$ exceeds $q_{t}(j)$. If $g_{t-1}$ is positive, $\xi_{t}(j)$ declines over time as long as the posted prices remain unchanged. This lowers the possibility that firm profits drop to zero. On the other hand, if $g_{t-1}$ is negative, $\xi_{t}(j)$ rises, which increases the possibility of the firm profits to drop to zero. However, a too high $g_{t-1}$ is much more harmful to firm values than a too low $g_{t-1}$. This is because, when $g_{t-1}$ is very high, firms anticipate a rapid decline in $\xi_{t}(j)$ in the 
future and accommodate a price higher than $q_{t}(j)$ by sacrificing current profits. On the other hand, when $g_{t-1}$ is very low, firm prices are always strictly below $q_{t}(j)$, enabling firms to earn positive profits. Therefore, the inverse $\mathrm{U}$ curve becomes asymmetric. In this simulation, the money growth rate $g_{t}$ that achieves the highest $\mu_{t}$ is almost equal to the mean of the money growth rate, $g$. This suggests that monetary policy rate shocks $\varepsilon_{t}^{M}$ dampen the entry and exit rate irrespective of whether they are positive or negative.

The bottom three panels show the firm value $v_{t}\left(\xi_{t}(j), q_{t}(j), g_{t}\right)$ by keeping two of the three arguments fixed at their mean. In the right panel, the dashed line represents the firm value at entry $v_{t}^{E}$, which is constant due to the free-entry condition (1). The firm value $v_{t}\left(\xi_{t}(j), q_{t}(j), g_{t}\right)$ is increasing with $q_{t}(j)$ because the markup increases. With respect to $\xi_{t}(j)$, a too low or too high value induces firms to reset their prices by paying the menu cost. In an intermediate region, firms do not reset their prices, and at one point, the firm value becomes the largest. As $g_{t}$ increases, the firm value tends to decrease, because firms have to make frequent price changes, which increases their menu cost payment and decreases firm value. However, this tendency does not hold for a very high $g_{t}$, because the rate of product substitution changes with $g_{t}$, as seen in the top left panel. A lower rate of product substitution increases the value of incumbent firms. Therefore, firm value can be both increasing and decreasing with respect to $g_{t}$.

Figure 3 shows the stationary density function of firms. Because firm distribution is threedimensional with respect to $\xi_{t}(j), q_{t}(j)$, and $g_{t}$, we draw the stationary density function with respect to one argument by summing the density function with respect to the other two arguments except for the last panel. In the top two panels, we confirm that firm distribution is normal with respect to both $q_{t}(j)$ and $g_{t}$. The bottom two panels display the firm distribution with respect to $\xi_{t}(j)$. The right panel is displayed by fixing $q_{t}(j)$ and $g_{t}$ at their mean. The firm density function is non-uniform: it is increasing with $\xi_{t}(j)$ in the $S s$ bound. When $\xi_{t}(j)$ equals its reset price $\xi_{t}^{*}(j)$, which is near the upper bound $(S)$ of $\xi_{t}(j)$, the density is the largest. This is because firms set their real prices at this level both when they reset their prices and when they enter the market. As time passes, $\xi_{t}(j)$ changes (mostly declines because $g_{t}$ is mostly positive). At the same time, some firms exit the market, and so the density decreases as $\xi_{t}(j)$ moves away from $\xi_{t}^{*}(j)$. When $\xi_{t}(j)$ falls to the lower bound $(s)$, firms reset their prices, and so the density below $s$ becomes zero. ${ }^{16}$ The bottom left panel represents the stationary density function with respect to $\xi_{t}(j)$, where the density functions like the bottom right panel are aggregated with respect to $q_{t}(j)$ and $g_{t}$. Because $q_{t}(j)$ and $g_{t}$ are stochastic, the stationary density function is more diverse than that in the bottom right panel.

\footnotetext{
${ }^{16}$ The dip at the left of $\xi_{t}^{*}(j)$ arises from the computation in discrete time. Starting from $\xi_{t}^{*}(j), \xi_{t}(j)$ does not move continuously but jumps by $e^{g_{t} \Delta t}$, where $\Delta t$ represents a time interval.
} 

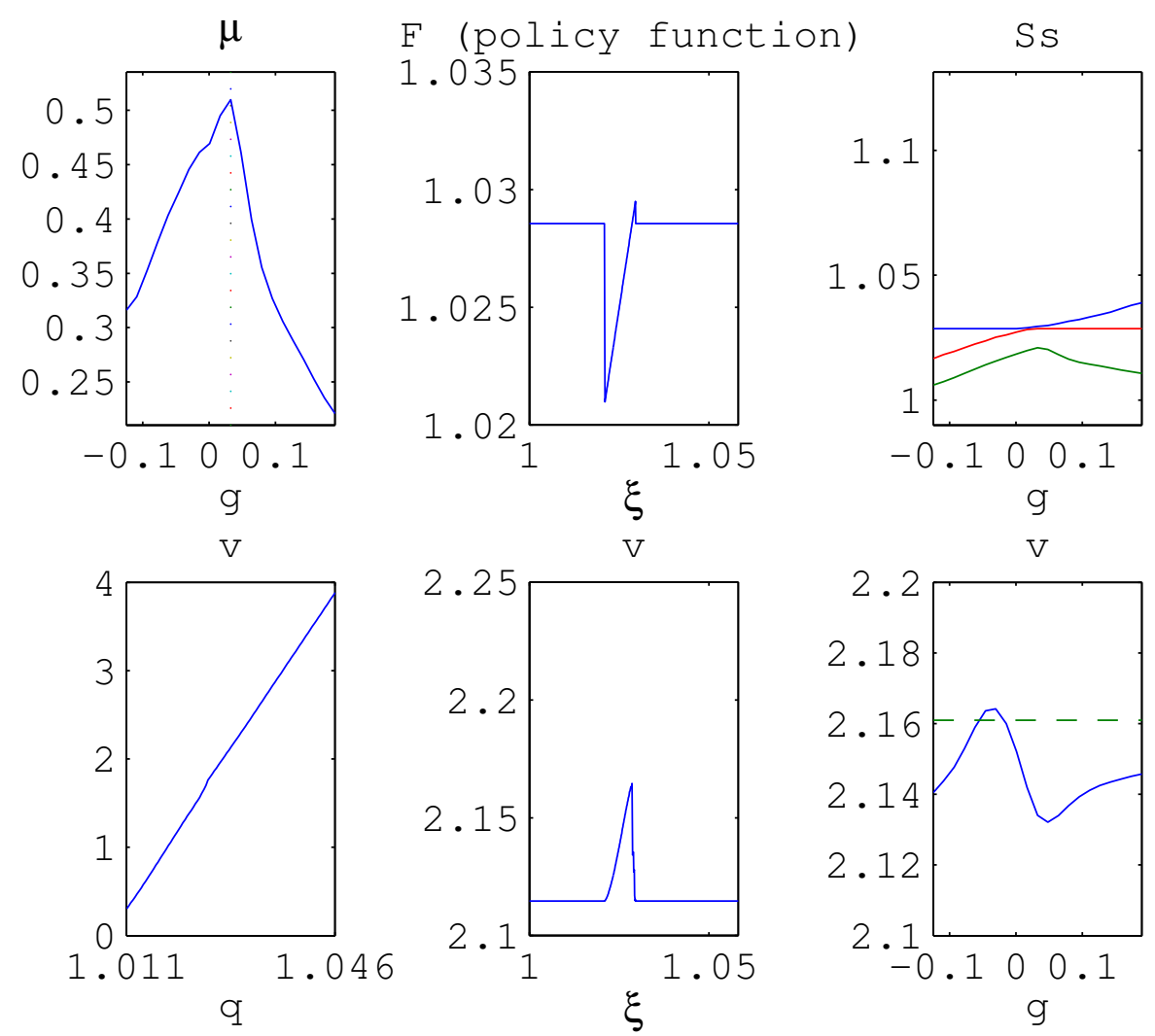

Figure 2: Key variables

Figure 4 depicts the density function with respect to the size of price changes. The top panel represents that for the matched sample (excluding product substitution), and the bottom one does that for new products (product substitution). In the latter case, we simply compare the posted prices without adjusting quality improvement. Clearly, the size of price changes is dispersed, in contrast to Golosov and Lucas (2007). Heterogeneous distribution motivates the work of Midrigan (2011). In our model, because $q_{t}(j)$ and $g_{t}$ are dispersed, the optimal markup comes to have heterogeneity. However, as discussed related to Table 1, our model fails to account for the size of price changes quantitatively.

\subsubsection{Transition Path}

Next, we investigate the transition path of the economy when $g_{t}$ changes unexpectedly by a sequence of monetary policy shocks. We assume that, initially in period $t=0$, firms are distributed according to their stationary distribution and $g_{t=0}$ equals its steady state level $g$.

For the economy, we assume positive shocks of the size of $\sigma_{M}$ lasting for a quarter from $t=14$ to 26 . Thereafter, $g_{t}$ converges to $g$ with the persistence of $\rho$. The transition path up to 

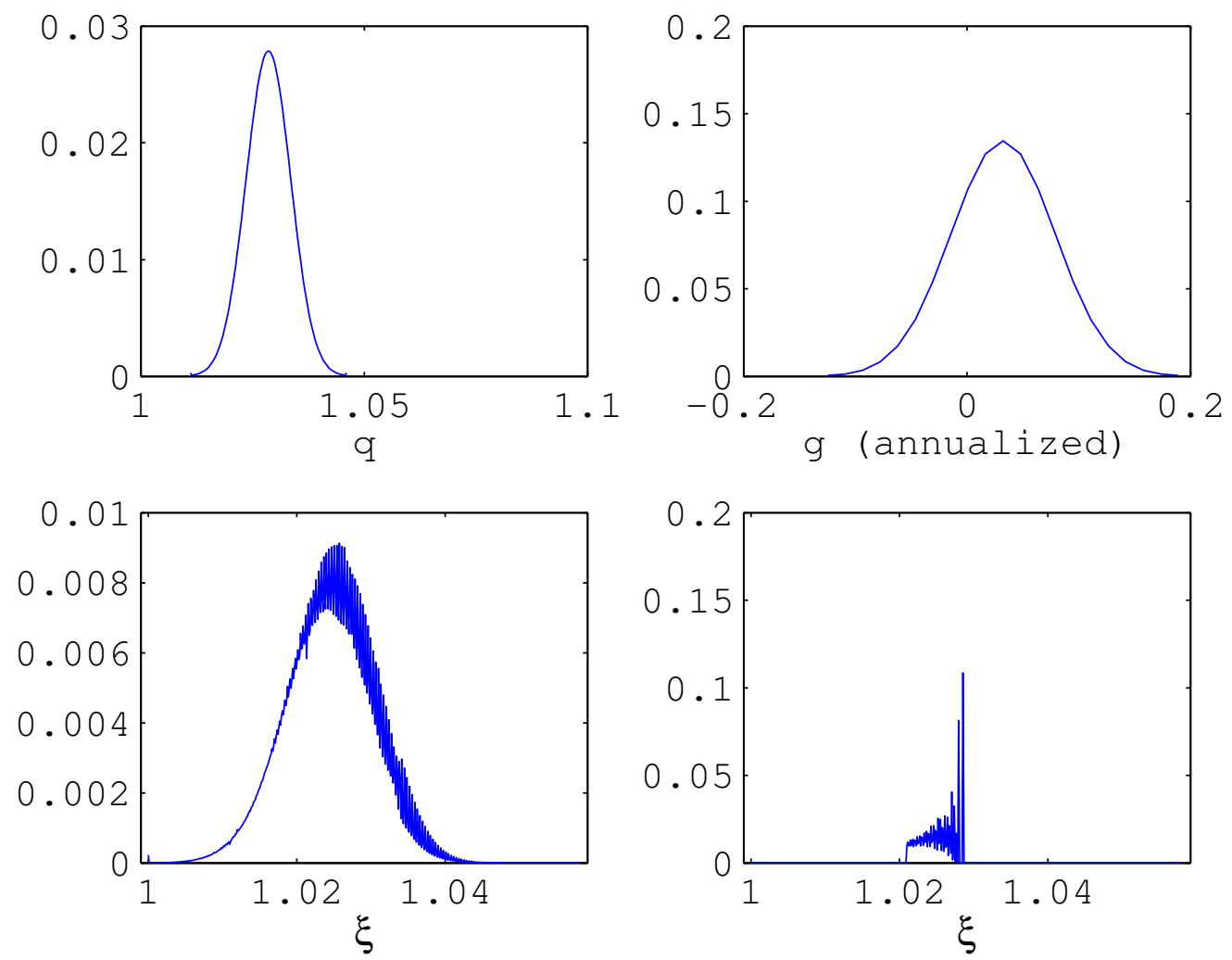

Figure 3: Stationary density function 

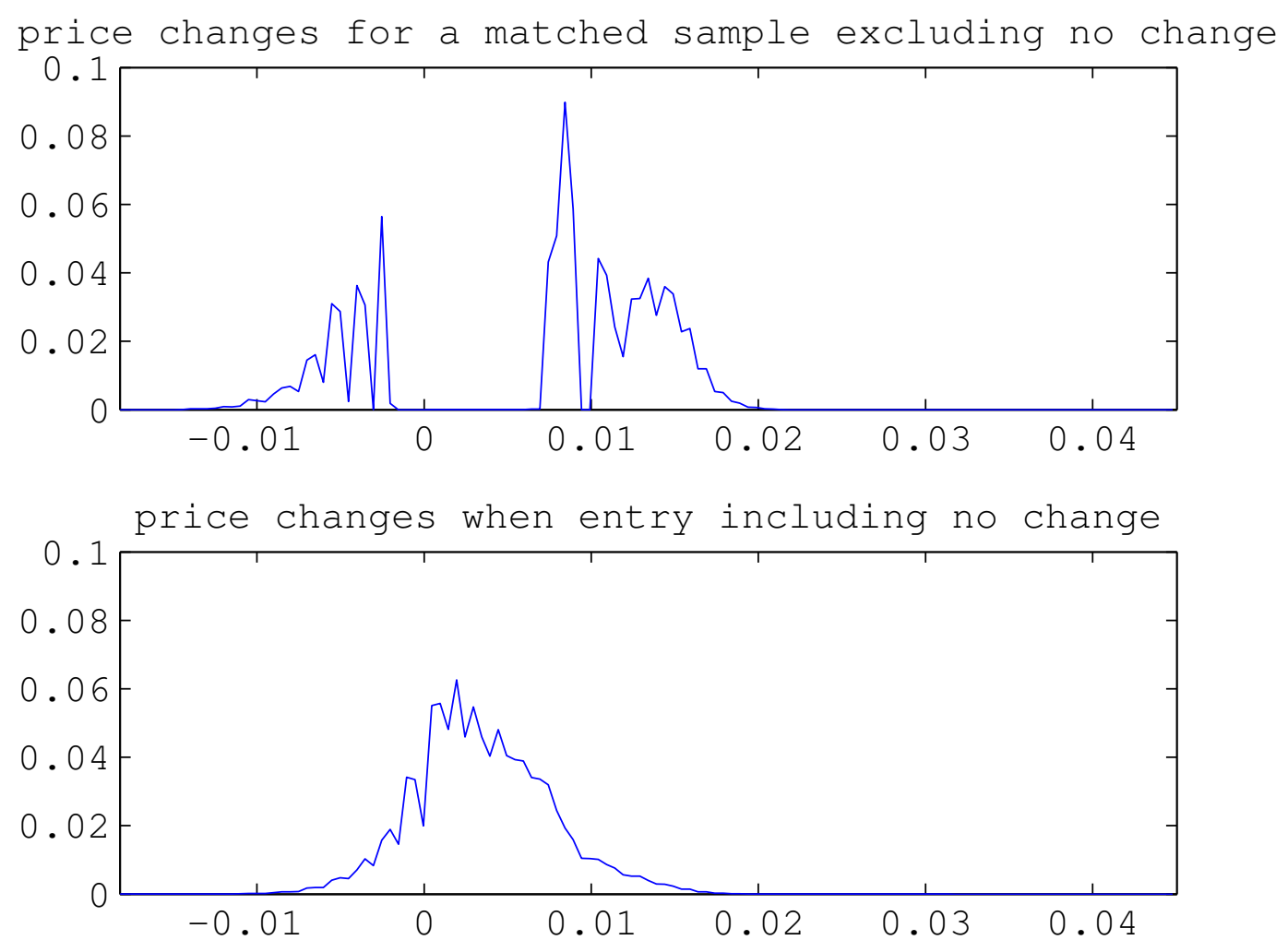

Figure 4: Size of price changes 
two years (104 weeks) is simulated. Figure 5 shows the result. The line with the dot represents the transition path in the face of shocks, whereas the dashed line represents the case for no monetary policy shock. We call the latter the benchmark. The bottom left panel displays the difference of consumption from the benchmark level. Note that even without shocks, the economy exhibits some fluctuations. This is because the stationary distribution in the presence of stochastic shocks differs from the distribution that would realize when there are no stochastic shocks.

As the top left panel shows, $g_{t}$ increases exogenously. Inflation occurs in the short run, but the size of inflation is smaller than the size of the increase in $g_{t}$. Thus, combined with equation (54), consumption increases, as the middle right and bottom left panels show. The size of the increase in consumption is comparable to the size of the increase in $g_{t} \cdot{ }^{17}$ In other words, the real effect of monetary policy is large. Such a result is in sharp contrast to Caplin and Spulber (1987) who argue that the real effect of monetary policy is null. In our model, firm distribution is non-uniform. The fraction of firms that are about to change prices, called marginal firms by Midrigan (2011), are less than the fraction of firms that just reset their prices or enter the market. Thus, a change in the extensive margin and in the aggregate price level are mitigated in response to a monetary policy shock. This generates the real effects of monetary policy. Such a result is consistent with Proposition 1 in Section 3.1 as well as Midrigan (2011) who points out the importance of a smaller number of marginal firms in obtaining a sizable real effect of monetary policy.

However, two adverse effects dampen consumption in the long run. First, the rate of product substitution falls, as shown in the middle left panel. The growth rate of consumption and the level of consumption are thus lowered. Second, when a monetary easing policy is conducted, the price increases in product substitution become larger. These effects dominate in the long run. The level of consumption falls below that in the benchmark in the long run.

To understand the mechanism in more detail, we decompose inflation rate movements as follows:

\footnotetext{
${ }^{17}$ Note that $g$ is shown in an annualized scale. Thus, to compare the level of consumption, we need to divide by 4 (quarterly) or 52 (weekly).
} 


$$
\begin{aligned}
\pi_{t}= & \left(1-\mu_{t}\left(g_{t-1}\right)\right) \cdot \int d \xi_{t-1} \int d q \cdot \Gamma_{t-1} \cdot \log \left(\frac{F\left(\xi_{t-1} e^{-g_{t}}, q, g_{t}\right)}{\xi_{t-1} e^{-g_{t}}}\right) \\
& +\mu_{t}\left(g_{t-1}\right) \cdot\left(\int d \Omega_{q} \cdot \log \left(\frac{F\left(\infty, q, g_{t}\right)}{q e^{-g_{t}}}\right)-\int d \xi_{t-1} \int d q \cdot \Gamma_{t-1} \cdot \log \xi_{t-1}\right) \\
= & g_{t} \\
& -\mu_{t}\left(g_{t-1}\right) \cdot \int d \Omega_{q} \cdot \log q \\
& -\left(\mu_{t}\left(g_{t-1}\right)-\mu\right) \cdot \int d \xi_{t-1} \int d q \cdot \Gamma_{t-1} \cdot \log \left(\frac{F\left(\xi_{t-1} e^{-g_{t}}, q, g_{t}\right)}{\xi_{t-1}}\right) \\
& +\left(\mu_{t}\left(g_{t-1}\right)-\mu\right) \cdot\left(\int d \Omega_{q} \cdot \log F\left(\infty, q, g_{t}\right)-\int d \xi_{t-1} \int d q \cdot \Gamma_{t-1} \cdot \log \xi_{t-1}\right) \\
& +(1-\mu) \cdot \int d \xi_{t-1} \int d q \cdot \Gamma_{t-1} \cdot \log \left(\frac{F\left(\xi_{t-1} e^{-g_{t}}, q, g_{t}\right)}{\xi_{t-1}}\right) \\
& +\mu \cdot\left(\int d \Omega_{q} \cdot \log F\left(\infty, q, g_{t}\right)-\int d \xi_{t-1} \int d q \cdot \Gamma_{t-1} \cdot \log \xi_{t-1}\right) .
\end{aligned}
$$

This equation suggests that four factors drive inflation rate changes : (i) the money growth rate $g_{t}$ (the first term on the right-hand side of the equation); (ii) the change in firm entry-exit rate (terms (56a)-(56c)); (iii) the change in real prices for existing firms, (56d); and (iv) the change in real prices due to firm entry, (56e). Figure 6 shows the decomposition of the impulse responses dividing the four factors.

Factor (iii) contributes to the positive short-run effect. This term would be zero if the prices were perfectly flexible, because real prices $\xi_{t}$ would stay constant at the level of $q_{t}(j)$. If the prices are sticky and the number of marginal firms is not too large, real prices for existing firms tend to fall when $g_{t}>0$. As $g_{t}$ increases and moves away from $g$, the size of the fall in real prices increases, and yields the positive effect on consumption, as highlighted in Section 3.1. ${ }^{18}$

For factor (ii), the second term on the right-hand side of the equation specifically indicates the real growth rate. Note that, in a deterministic case, this is equal to $a=\mu \log q$. The monetary easing shock lowers $\mu_{t}$, and, in turn, the growth rate of consumption, as highlighted in Section 3.2. This constitutes the first adverse effect of monetary easing.

Factor (iv) represents the second adverse effect of monetary easing. See the top right panel of Figure 2. As $g_{t}(>0)$ increases, the lower bound of no price revision $s$ declines, while the reset price $\xi_{t}^{*}$ is irresponsive. Because real prices generally lie between $s$ and $\xi_{t}^{*}$ for $g_{t}>0$, this suggests that, given $q_{t}(j)$, the average real price falls as $g_{t}$ increases. Intuitively speaking, under

\footnotetext{
${ }^{18}$ Interestingly, we find asymmetric responses to a monetary policy shock. When a monetary policy shock is negative, its short-run effect on consumption is again positive. This arises because the Ss band is widened for $g_{t}<g$, as shown in the top right panel of Figure 2. Marginal firms decrease sufficiently to make the real prices fall, and, as a result, consumption increases.
} 
sticky prices, old replaced products are on average sold below their optimal markup prices that would prevail under flexible prices. Thus, even though quality is improved by new products, price increases become larger and dampens the consumption level permanently.

Summing up these factors, we draw Figure 6. The four panels in the left column display the decomposition of the inflation rate into (i) to (iv). The panels in middle and right columns display the decomposition of the real growth rate and the difference of consumption from that in the benchmark, respectively, into (ii) to (iv). Because the real growth rate $a_{t}$ equals $g_{t}-\pi_{t}$, factor (i) is completely deducted when it comes to the effect on the real side of the economy and factors (ii) to (iv) affect the real side of the economy with the opposite sign to which they do the inflation rate. The figure, in particular, the right columns, demonstrates that factor (ii), that is, the decline in the firm entry-exit rate, has the largest effect on the real economic activity in the long-run.

Finally, it is worth noting that permanent monetary easing decreases the level of consumption further. If a permanent monetary easing is conducted and this policy is anticipated by the public, such a policy is interpreted not as the transitory easing shock but as a permanent increase in $g$. Then, as Figure 1 shows, not just the level, but the growth rate of consumption as well decline in the long run. This is harmful to welfare.

\subsubsection{Robustness}

We checked the robustness of our results. For different timings, sizes, and duration of shocks, our results do not change qualitatively. When we use a larger menu cost, the frequency of price changes becomes closer to that in Nakamura and Steinsson (2008) and other results do not change qualitatively. When we use a smaller menu cost, as reported in Midrigan (2011), that is, $\kappa=0.022$, the frequency of price changes moves away from that in Nakamura and Steinsson (2008), but other results do not change qualitatively. However, when we use an even smaller menu cost than reported in Levy et al. (1997), that is, $\kappa=0.007$, the transition path qualitatively changes. For the monetary easing shock, the level of consumption increases not only in the short run but also in the long run. However, in this calibration, the weekly frequency of price changes increases to 0.23 and the role played by monetary policy diminishes.

\section{Concluding Remarks}

In this study, we illustrated a tradeoff between the short-run positive and long-run negative effects of monetary easing using a dynamic stochastic general equilibrium model. The model reveals that monetary easing increases the level of consumption due to price stickiness. How- 

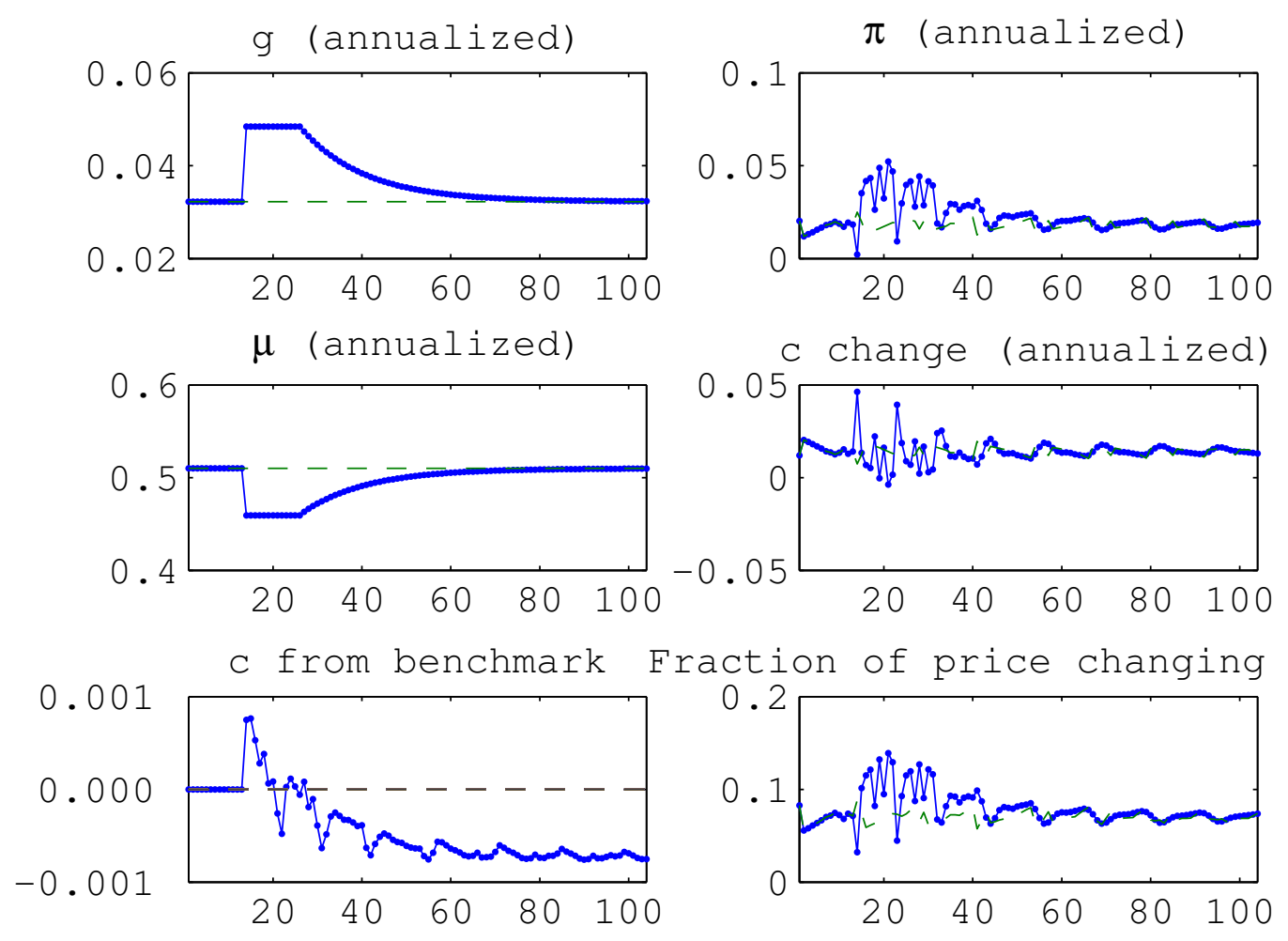

Figure 5: Transition path: $+1 \sigma$ shock for a quarter 

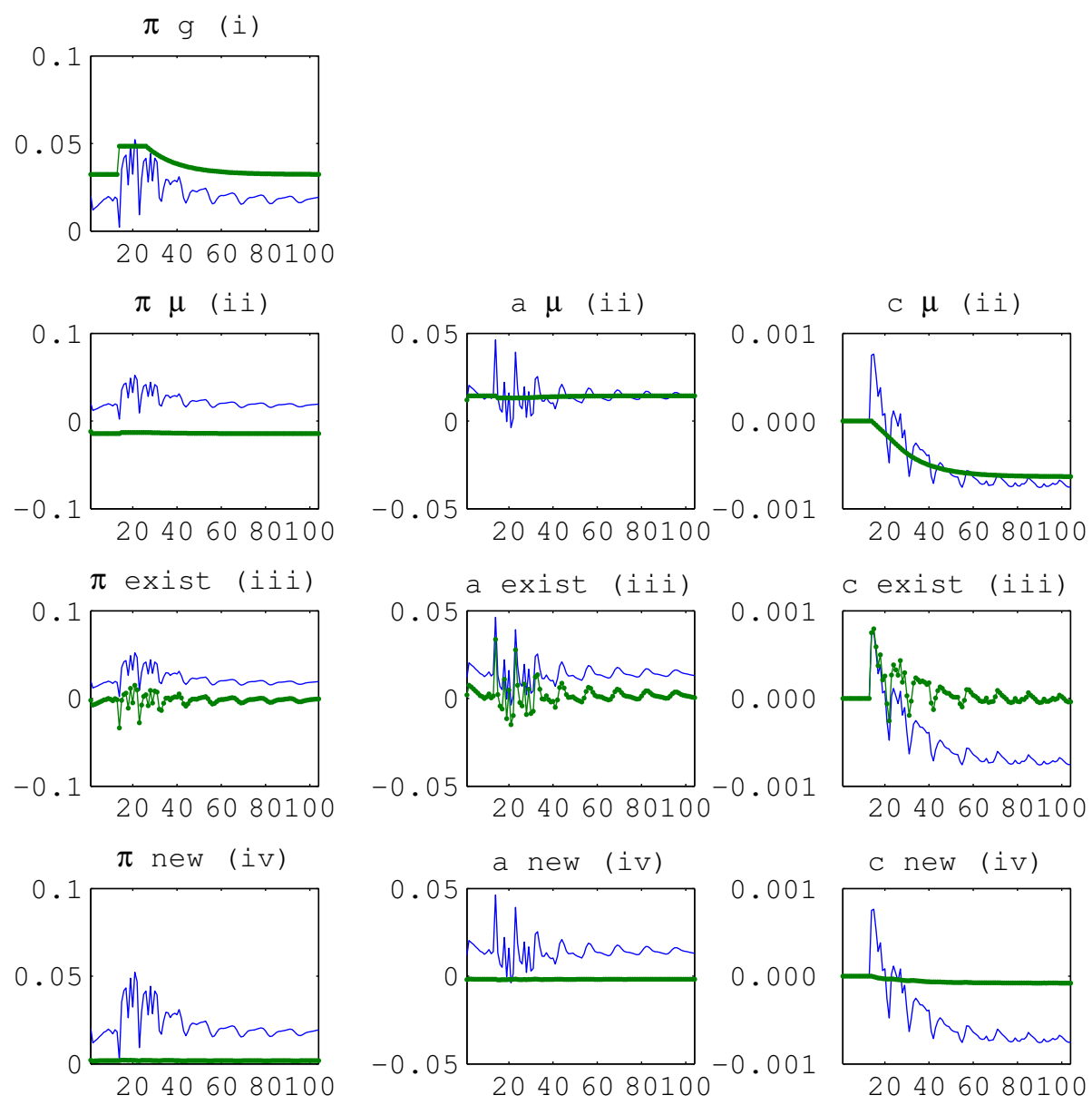

Figure 6: Decomposition of impulse responses 
ever, it lowers the frequency of creative destruction (product substitution), and, in turn, the growth rate of consumption, because inflation reduces the reward for innovation via menu cost payments. Moreover, the price increases in product substitution become larger by monetary easing shock, which results in a fall in consumption. Although monetary easing increases consumption in the short run, such adverse effects, in particular the fall in creative destruction rate, dominate in the long-run and lower consumption permanently.

As the direction of future research, our analysis should be improved to match actual price data, namely, the frequency of price changes, the size of price changes, the rate of product substitution, and the size of price changes when products are substituted. In terms of model setup, combining the features in Golosov and Lucas (2007), Nakamura and Steinsson (2010), and Midrigan (2011) will be a promising direction although this could make numerical computation hard.

Another direction is firm dynamics and the reallocation efficiency on growth paths. Because a monetary shock has different impacts on incumbents and potential entrants in this model, monetary policy may affect firm size distribution and the decomposition of real growth if we allow firms to have multiple product lines as in Klette and Kortum (2004) and Lentz and Mortensen (2008).

\section{References}

Acemoglu, D., U. Akcigit, N. Bloom, and W. R. Kerr (2013). Innovation, Reallocation and Growth. NBER Working Papers 18993, National Bureau of Economic Research, Inc.

Amano, R., T. Carter, and K. Moran (2012). Inflation and Growth: A New Keynesian Perspective. Working Papers 12-23, Bank of Canada.

Arato, H. (2009). Long-run relationship between inflation and growth in a New Keynesian framework. Economics Bulletin 29(3), 1863-1872.

Bilbiie, F. O., I. Fujiwara, and F. Ghironi (2014). Optimal monetary policy with endogenous entry and product variety. Journal of Monetary Economics 64(0), 1 - 20.

Bils, M. (2009). Do Higher Prices for New Goods Reflect Quality Growth or Inflation? The Quarterly Journal of Economics 124(2), 637-675.

Bils, M. and P. J. Klenow (2004). Some Evidence on the Importance of Sticky Prices. Journal of Political Economy 112(5), 947-985. 
Caballero, R. J., T. Hoshi, and A. K. Kashyap (2008). Zombie lending and depressed restructuring in japan. American Economic Review 98(5), 1943-77.

Caplin, A. S. and D. F. Spulber (1987). Menu Costs and the Neutrality of Money. The Quarterly Journal of Economics 102(4), 703-25.

Chu, A. C. and G. Cozzi (2014). R\&D and Economic Growth in a Cash-in-Advance Economy. International Economic Review 55, 507-524.

Funk, P. and B. Kromen (2010). Inflation and Innovation-Driven Growth. The B.E. Journal of Macroeconomics 10(1), 1-52.

Golosov, M. and R. E. Lucas, Jr. (2007). Menu Costs and Phillips Curves. Journal of Political Economy 115, 171-199.

Grossman, G. M. and E. Helpman (1991). Innovation and Growth in the Global Economy. MIT Press.

Klette, T. J. and S. Kortum (2004). Innovating Firms and Aggregate Innovation. Journal of Political Economy 112(5), 986-1018.

Krusell, P. and A. A. Smith (1998). Income and Wealth Heterogeneity in the Macroeconomy. Journal of Political Economy 106(5), 867-896.

Lentz, R. and D. T. Mortensen (2008). An Empirical Model of Growth Through Product Innovation. Econometrica 76(6), 1317-1373.

Levy, D., M. Bergen, S. Dutta, and R. Venable (1997). The Magnitude of Menu Costs: Direct Evidence from Large U.S. Supermarket Chains. The Quarterly Journal of Economics 112(3), $791-825$.

Midrigan, V. (2011). Menu costs, multiproduct firms, and aggregate fluctuations. Econometrica $79(4), 1139-1180$.

Nakamura, E. and J. Steinsson (2008). Five Facts about Prices: A Reevaluation of Menu Cost Models. The Quarterly Journal of Economics 123(4), 1415-1464.

Nakamura, E. and J. Steinsson (2010). Monetary Non-Neutrality in a Multisector Menu Cost Model. The Quarterly Journal of Economics 125(3), 961-1013.

Oikawa, K. and K. Ueda (2015). The Optimal Inflation Rate under Schumpeterian Growth. CAMA Working Papers 2015-14, Centre for Applied Macroeconomic Analysis, Crawford School of Public Policy, The Australian National University. 
Sheshinski, E. and Y. Weiss (1977). Inflation and Costs of Price Adjustment. Review of Economic Studies 44(2), 287-303.

Vaona, A. (2012). Inflation And Growth In The Long Run: A New Keynesian Theory And Further Semiparametric Evidence. Macroeconomic Dynamics 16(01), 94-132. 